\title{
QTL for mohair traits in South African Angora goats
}

\author{
C. Visser ${ }^{a, *}$, E. Van Marle-Köster ${ }^{a}$, H. Bovenhuis ${ }^{b}$, R.P.M.A. Crooijmans ${ }^{b}$ \\ a Department of Animal E Wildlife Sciences, University of Pretoria, South Africa \\ ${ }^{\mathrm{b}}$ Animal Breeding and Genomics Centre, Wageningen University, Wageningen, The Netherlands
}

\section{A R T I C L E I N F O}

\section{Article history:}

Received 6 April 2011

Received in revised form 20 May 2011

Accepted 26 May 2011

Available online $\mathrm{xxx}$

\section{Keywords:}

Angora goats

QTL

Mohair

Quality traits

\begin{abstract}
A B S T R A C T
The aim of this study was to identify QTL associated with mohair production and quality traits in South African Angora goats. Limited research has been performed on QTL influencing the economically important mohair traits of Angora goats. Twelve half-sib Angora goat families with an average of 58 offspring per sire were genotyped for 88 microsatellites covering 22 autosomes. Phenotypic data was collected at second and third shearing for males and females respectively. A linkage analysis was performed under the half-sib model using the least squared regression approach of GridQTL. Three putative QTL were detected for fleece weight on $\mathrm{CHI} 2,5$ and 24, which corresponds with the locations of keratin and keratin-associated proteins. This study detected two putative QTL associated with mohair fibre diameter (on CHI 4 and 24, respectively), which is the most important pricedetermining trait. Four QTL were detected on CHI 8, 13, 18 and 20 which influence both comfort factor and spinning fineness. The variance explained by the QTL ranged between $6.9 \%$ for fibre diameter and $33.6 \%$ for standard deviation along the length of the staple. These results reveal segregation of QTL influencing mohair production and quality, and contribute to the understanding of the genetic variation of mohair traits.
\end{abstract}

(c) 2011 Elsevier B.V. All rights reserved.

\section{Introduction}

DNA technology has resulted in the identification of loci and chromosomal regions that contribute to phenotypic variation in economically important traits (e.g. Dekkers, 2004). Identifying and confirming Quantitative Trait Loci (QTL) is the first step in the process that could lead to Marker Assisted Selection (MAS) or Gene Assisted Selection (GAS). Since the first QTL mapping studies in livestock (Georges et al., 1995) the advantages and complications of implementing genomic information in genetic improvement programs have been well documented (Dekkers, 2004; Alan \& Smith, 2008; Goddard, 2009). Using genomic information in selection especially has the potential to increase the rate of genetic progress for traits with low

\footnotetext{
* Corresponding author. Tel.: +27 12420 3268; fax: +27 124203290 E-mail address: carina.visser@up.ac.za (C. Visser).
}

heritability, sex-limited traits and those that are difficult to measure (Pollak, 2005). Over the past two decades QTL have been confirmed in several farm animal species and some are applied in MAS, i.e. meat tenderness and marbling in beef cattle and meat quality and feed intake in pigs (Jeon et al., 2006). The benefits of MAS are driven by an increased selection accuracy, and the successful implementation thereof is dependent amongst others on the economic relevance of the trait studied (e.g. Van der Werf, 2007).

In goats QTL studies have been mainly limited to disease resistance and milk proteins. Implementation of MAS in goats has been limited to the selection against diseases like scrapie, CAEV and Johne's disease (Dodds et al., 2007) and for casein genes (Van der Werf, 2007). Wool and fibre traits seem to remain a challenge, despite moderate to high heritability for economically important traits like fleece weight and fibre diameter. The unfavourable genetic correlation that exists between fleece weight and fibre diameter as 
well as with body weight in wool sheep and mohair goats have prompted several studies on candidate genes (Purvis \& Franklin, 2005).

The genetic improvement of production and quality mohair traits of Angora goats in South Africa has been based on phenotypic information for the past two decades. Emphasis was originally placed only on fibre diameter, but the unfavourable positive correlation with body weight resulted in small, unthrifty animals with low survivability. The national selection strategy was changed to include three primary traits, namely fibre diameter (the most important price-determining trait), fleece weight and body weight which were combined into a selection index (Snyman \& Olivier, 1996). This strategy was evaluated in 2002 (Snyman, 2002) and confirmed to be successful in improving production and quality of the national clip, while maintaining body weight. If QTL explaining significant fractions of the genetic variance in these traits could be identified, it should however lead to increased accuracy of EBVs with a corresponding faster rate of genetic improvement (Van der Werf, 2007). QTL mapping should also lead to increased knowledge of the underlying molecular mechanisms of fibre and fleece characteristics which could result in more efficient selection programs on the long term (Purvis \& Jeffery, 2007).

Although several QTL identification studies have been undertook for wool sheep (Allain et al., 2006; Bidinost et al., 2006, 2008; Roldan et al., 2010), relatively few studies have been conducted to identify linkage with goat fibre traits. Chromosome segments that affect mohair were identified by Cano et al. (2007) in Argentinean Angora goats and this resulted in further investigation into goat chromosome 19 (Cano et al., 2009a). These results, together with the QTL affecting conformation traits in Angora goats (Marrube et al., 2007) paved the way for a candidate gene approach by Mohammed Abadi et al. (2009) for improved cashmere yield in Rayini goats. Recently QTL affecting fleece traits were identified by Debenedetti et al. (2010) on CHI 5 in a backcross Angora $\times$ Creole population. Only one study (Cano et al., 2009b) has identified QTL for fleece weight and fibre diameter which are the most important pricedetermining traits of mohair. As new technology (i.e. OFDA measurements) was developed, it became clear that newly measured quality traits (e.g. coefficient of variation, comfort factor, spinning fineness) could possibly play a role in breeding objectives (Visser et al., 2009). Traits that could result in a more uniform, fine mohair staple are especially of increasing importance and are currently being considered for inclusion in the South African Angora goat selection index. Very few of these quality traits have been included in any of the previous studies.

Candidate genes for wool production have been studied quite extensively (Itenge-Mweza et al., 2007; Gong et al., 2010; Jin et al., 2010). This is due to the unfavourable genetic correlation between fibre diameter and fleece weight (the two most important price-determining factors in natural animal-produced fibres) and the need for natural fibres with novel properties (Purvis \& Franklin, 2005). The same motivation applies to the study of genes influencing mohair traits. The South African mohair clip contributes in excess of $50 \%$ to the global market. The constant pressure from synthetic fibres necessitates the need for a high quality clip with little variation within and between fleeces. The production of mohair with new and novel properties might expand the niche market for this quality product. This study aimed to identify chromosome segments associated with product and quality traits of mohair.

\section{Materials and methods}

\subsection{Animals and phenotypic data}

The data resource consisted of a total of 695 offspring from twelve Angora bucks originating from four different farms. Family sizes were on average 58 and ranged between 16 and 130 offspring per sire. Families were generated over a three-year period (2004-2006) during which blood samples were routinely collected and stored in a DNA bank for small stock research (Grootfontein Agricultural Development Institute, National Department of Agriculture).

Phenotypes were recorded on second (8-12 months) or third (16-18 months) shearings. Bucks were sheared at eight to 12 months, while the does were sheared at 16-18 months. Only one shearing record per animal was included in the analysis. Greasy fleece weight (measured to the nearest $0.1 \mathrm{~kg}$ ) was determined just after shearing. Individual midrib samples were taken and a single sub-sample (prepared from three different locks) was analysed for each individual for determination of average fibre diameter (FD; $\mu \mathrm{m})$, coefficient of variation of fibre diameter (CVFD; \%), standard deviation of fibre diameter (SDFD; $\mu \mathrm{m}$ ), comfort factor (CF; \%), spinning fineness (SF; $\mu \mathrm{m})$ and standard deviation of fibre diameter along the length of the staple (SDA; $\mu \mathrm{m})$. The quality traits were measured using OFDA2000 technology, as previously described in Visser et al. (2009). One breeder did not send in samples for further testing, and thus the number of records used for the quality traits were less than for FW and FD.

\subsection{DNA and genotyping}

DNA was extracted from $100 \mu \mathrm{l}$ whole blood samples using respectively the Qiagen DNEasy Tissue kit and the Invisorb blood mini HTS kit (Invitek) for the XtractorGene (Corbett Robotics) according to the protocols of the respective manufacturers.

One hundred and thirty four microsatellite markers were selected from the existing goat map database (http://locus.jouy.inra.fr/cgibin/lgbc/mapping/common/intro2.pl?BASE=goat) and previously published literature to obtain sufficient genome coverage. Eighty-eight markers spaced over 22 autosomes were finally selected based on level of polymorphism, heterozygosity levels, allele size range and amplification success (a complete list of these parameters were reported in Visser et al., 2010). Poor amplification and little informativeness of some markers limited the aim of at least three markers per chromosome. The markers were divided into eight genotyping sets, averaging twelve markers per set. PCR reactions were performed in a 384 well i-cycler (Bio-rad) or Ti Thermocycler (Biometra) in a $6 \mu \mathrm{l}$ final volume using $100 \mathrm{ng}$ DNA, $2.94 \mu \mathrm{l}$ of the ABgene ${ }^{\circledR}$ PCR Master Mix (ABGene, UK) and $0.03 \mu$ l reverse and forward primer each of $40 \mathrm{pmol} / \mu \mathrm{l}$. The PCR amplification was conducted the following conditions: $95^{\circ} \mathrm{C}$ for $5 \mathrm{~min}$, followed by 35 cycles of $96^{\circ} \mathrm{C}$ for $30 \mathrm{~s}, 45 \mathrm{~s}$ at annealing temperature and $90 \mathrm{~s}$ at $72^{\circ} \mathrm{C}$ with a final extension step of $10 \mathrm{~min}$ at $72^{\circ} \mathrm{C}$. PCR products were analysed using an automated ABI 373/377 sequencer (Perkin-Elmer) and allele calling was performed with GeneMapper (Applied Biosystems).

\subsection{Statistical analysis}

Phenotypic records were pre-adjusted for herd (levels 1-4), year of birth (2004, 2005 or 2006), birth status (single or twin) and sex. QTL analysis was performed using half-sib regression (Knott et al., 1996) as implemented in the GridQTL software (Seaton et al., 2006). The following least-squares regression model used was:

$y_{i j}=$ Sire $_{i}+\beta_{i} x_{i j}+e_{i j}$

where $y_{i j}$ is the phenotype (corrected for fixed effects) of individual $i j$, offspring of sire $i$, Sire $e_{i}$ is the mean of sire family $i, \beta_{i}$ is the allele substitution effect of the QTL within family $i, x_{i j}$ is the probability that the animal $i j$ inherited the first allele of sire $i$ and $e_{i j}$ is the residual. 
Table 1

Summary statistics (means $\pm \mathrm{SD}$ ) for the fleece traits of the 12 Angora goat families

\begin{tabular}{|c|c|c|c|c|c|c|c|c|c|}
\hline Family & $n$ & FW (kg) & $\mathrm{FD}(\mu \mathrm{m})$ & $n$ & $\operatorname{SDFD}(\mu \mathrm{m})$ & CVFD (\%) & $\mathrm{CF}(\%)$ & $\mathrm{SF}(\mu \mathrm{m})$ & $\mathrm{SDA}(\mu \mathrm{m})$ \\
\hline 1 & 67 & $1.27 \pm 0.40$ & $28.24 \pm 3.16$ & 4 & $8.15 \pm 1.74$ & $31.88 \pm 4.17$ & $78.78 \pm 14.97$ & $27.63 \pm 4.15$ & $1.68 \pm 1.23$ \\
\hline 2 & 86 & $1.20 \pm 0.29$ & $26.80 \pm 2.51$ & 25 & $7.76 \pm 0.99$ & $28.64 \pm 3.01$ & $71.52 \pm 13.06$ & $28.44 \pm 2.82$ & $1.18 \pm 0.42$ \\
\hline 3 & 79 & $1.27 \pm 0.40$ & $27.09 \pm 2.61$ & 11 & $7.99 \pm 0.99$ & $28.11 \pm 3.44$ & $68.45 \pm 13.78$ & $29.66 \pm 2.14$ & $1.51 \pm 1.00$ \\
\hline 4 & 91 & $1.35 \pm 0.43$ & $25.84 \pm 3.24$ & 40 & $8.35 \pm 1.05$ & $31.66 \pm 2.99$ & $73.45 \pm 12.82$ & $28.55 \pm 3.12$ & $1.52 \pm 0.68$ \\
\hline 5 & 130 & $1.64 \pm 0.44$ & $29.84 \pm 2.53$ & 129 & $7.72 \pm 0.89$ & $25.98 \pm 2.85$ & $58.57 \pm 13.50$ & $30.41 \pm 2.44$ & $1.27 \pm 0.38$ \\
\hline 6 & 80 & $2.10 \pm 0.56$ & $32.60 \pm 2.99$ & 80 & $8.71 \pm 1.14$ & $26.80 \pm 3.15$ & $46.34 \pm 15.20$ & $33.47 \pm 2.95$ & $1.60 \pm 0.50$ \\
\hline 7 & 16 & $1.73 \pm 0.45$ & $29.08 \pm 2.10$ & 0 & - & - & - & - & - \\
\hline 8 & 17 & $2.10 \pm 0.37$ & $29.46 \pm 2.82$ & 0 & - & - & - & - & - \\
\hline 9 & 29 & $1.59 \pm 0.42$ & $28.28 \pm 2.01$ & 0 & - & - & - & - & - \\
\hline 10 & 23 & $2.47 \pm 0.47$ & $29.83 \pm 1.94$ & 0 & - & - & - & - & - \\
\hline 11 & 33 & $1.22 \pm 0.18$ & $25.67 \pm 2.12$ & 32 & $7.22 \pm 1.16$ & $27.97 \pm 3.12$ & $78.08 \pm 8.40$ & $26.83 \pm 2.59$ & $1.08 \pm 0.33$ \\
\hline 12 & 44 & $1.32 \pm 0.23$ & $25.14 \pm 2.13$ & 44 & $6.33 \pm 0.96$ & $25.17 \pm 2.70$ & $81.71 \pm 9.32$ & $25.43 \pm 2.37$ & $1.02 \pm 0.35$ \\
\hline
\end{tabular}

The 10,000 permutations were used to generate a test-statistic under the null hypothesis and to determine thresholds for both chromosomewide and experiment-wide Type 1 error rates. The confidence intervals of the QTL locations were estimated using 2000 bootstraps. The QTL variance was calculated according to Knott et al. (1996).

\section{Results}

The phenotypic averages for the mohair product and quality traits of the 12 families belonging to four different breeders are shown in Table 1 . Families 7-10 were kept by one breeder and as no quality traits were recorded for these animals only FW and FD were included for them. Families 5 and 6 had the highest means for FD (coarse fibres) and SF and correspondingly the lowest means for CF. Families 8 and 10 showed the highest means for FW, with little variation between the herds for FD. The lowest means for FD and SF was recorded in families 11 and 12, with correlated low values as expected for FW and high values for CF.

In Table 2 the markers used in the analyses, their locations and genome coverage were shown. Five chromosomes (CHI 9, 21, 22, 28 and 29) were excluded from the study, as only one marker was located on each of these chromosomes and consequently interval mapping was not possible. The intervals between consecutive markers ranged between 1 and $51 \mathrm{cM}$ with an average marker interval of $23.0 \mathrm{cM}$, covering a total of $1253 \mathrm{cM}$. The number of informative families used in the GridQTL analysis varied between 11 and 12 per chromosome. The lowest average percentage of heterozygous sires over loci on a chromosome was $53 \%$ ( $\mathrm{CHI} 8$ ), increasing to $80 \%$ on $\mathrm{CHI} 25$. The information content across chromosomes ranged between $35 \%$ on CHI 1 and 69\% on CHI 26.

This study identified QTL for mohair traits on thirteen chromosomes at the chromosome-wide significance level (Table 3). At least one region of interest was detected for each trait included in the analyses. In Table 3 the $F$ statistics, location of the QTL, QTL effect and QTL variance are given. 95\% confidence intervals frequently exceeded $50 \mathrm{cM}$ and usually included the whole chromosome, and were thus not reported.

Thirteen putative QTL regions were found in total for the seven traits. Three QTL were identified for FW on chromosomes 2, 5 and 24 respectively. Putative QTL for FD were identified on chromosomes 4 and 24. One putative QTL was found for CVFD, SDFD and SDA each on chromosomes 25,
3 and 1 respectively. Chromosomes 8, 13, 18 and 20 each showed segregation for a QTL for both CF and SF. On chromosomes 12 and 16 two more putative QTL were identified for CF. Only one putative QTL (for FW, on chromosome 24) could be identified with $p<0.01$ chromosome-wide significance, while all other QTL complied to $p<0.05$, at chromosome-wide significance.

The estimates of QTL contributions to the phenotypic variance ranged between $6.9 \%$ for FD on $\mathrm{CHI} 24$ and $33.6 \%$ for SDA on CHI 1. Most of the QTL variance estimates were between 9 and 14\%. The QTL effects (scaled by the standard deviation of the trait) varied from -1.4 to 4.6 standard deviation units for different traits and families. The plots of the $F$-statistics for the chromosomes with more that one putative QTL are shown in Fig. 1.

\section{Discussion}

In this study out-bred populations were analysed, in contrast to the back-cross populations often used in QTL investigations. Findings reported therefore represent genes segregating in the South African Angora goat population and results can be exploited by means of selection. Heritability estimates reported for these traits in the South African Angora goat population ranged between 0.14(SDA) and 0.63 (CF) (Visser et al., 2009). The size of the outbred population directly affects the statistical power of the experimental design (Van der Werf et al., 2007). It was estimated that this study (consisting of 12 sires with an average of 58 offspring, average heritability of 0.35 , Type I error of 0.05 ) will achieve a power of $70 \%$ to detect a QTL effect of 0.5 phenotypic SD (Weller et al., 1990). Most of the QTL detected had larger effects than this. This design was similar to those of Cano et al. (2007), Bidinost et al. (2008), Cano et al. (2009b), Mohammed Abadi et al. (2009) and Roldan et al. (2010).

The phenotypic averages over families for FW and FD were in the same range as those previously reported by Snyman and Olivier (1996, 1999) and Visser et al. (2009) on South African Angora goats. Differences between families are due to herd effects, breeders following different selection strategies and placing emphasis on varying selection criteria, with limited genetic linkages between farms. Previous reports on QTL associated with mohair traits are limited to one research group (Cano et al., 2007, 2009a,b; Debenedetti et al., 2010) and traits investigated varied 
Table 2

Genome coverage of microsatellite markers.

\begin{tabular}{|c|c|c|c|c|}
\hline $\mathrm{CHI}$ & $\mathrm{N}$ markers & $\begin{array}{l}\mathrm{N} \text { informative } \\
\text { families }\end{array}$ & $\mathrm{IC}^{\mathrm{a}}$ & Markers (position in cM) \\
\hline 1 & 6 & 12 & 0.35 & BM1312 (0), BM3205 (39), CSSM19 (45), CSSM32 (92), MAF64 (113), INRA11 (137) \\
\hline 2 & 4 & 12 & 0.40 & BMS2782 (0), OARFCB11 (1), INRA40 (11), SRCRSP24 (62) \\
\hline 3 & 4 & 11 & 0.47 & CSSM54 (0), MCM58 (30), INRA3 (58), INRA6 (74) \\
\hline 4 & 6 & 12 & 0.50 & OARHH64 (0), OARCP26 (41), MAF50 (50), OARHH35 (82), BMS1788 (97), MAF70 (129) \\
\hline 5 & 7 & 12 & 0.42 & OARFCB5 (0), LSCV25 (12), BMS1248 (15), BM2830 (65), BMC1009 (90), ILSTS34 (100), BM321 (121) \\
\hline 6 & 6 & 12 & 0.58 & BM143 (0), BM415 (18), BM1329 (39), BM4621 (67), ILSTS087 (74), SRCRSP08 (81) \\
\hline 7 & 3 & 11 & 0.46 & INRABERN192 (0), OARAE129 (18), MCM527 (27) \\
\hline 8 & 3 & 11 & 0.57 & CSSM47 (0), MCM64 (8), SRCRSP10 (26) \\
\hline 11 & 3 & 11 & 0.36 & INRA177 (0), OARCP34 (4), ILSTS45 (41) \\
\hline 12 & 5 & 12 & 0.50 & BMS712 (0), INRA5 (24), BMS2252 (43), SRCRSP9 (59), ILSTS33 (77) \\
\hline 13 & 3 & 11 & 0.44 & IL2RA (0), BMC1222 (25), ILSTS59 (31) \\
\hline 14 & 2 & 11 & 0.56 & BM4630 (0), ILSTS11 (11) \\
\hline 16 & 3 & 11 & 0.39 & BM719 (0), BM121 (18), HUJ614 (68) \\
\hline 17 & 4 & 12 & 0.52 & OARVH98 (0), OARFCB48 (17), ILSTS58 (51), BM8125 (57) \\
\hline 18 & 3 & 12 & 0.64 & INRA210 (0), INRA63 (11), MCM104 (26) \\
\hline 19 & 4 & 11 & 0.40 & MCM210 (0), BMS745 (33), LSCV36 (44), OARFCB193 (46) \\
\hline 20 & 4 & 12 & 0.44 & MAF214 (0), TGLA304 (11), BM1225 (32), BM3517 (60) \\
\hline 23 & 5 & 12 & 0.63 & OARCP73 (0), OLA-DRB (8), BM1818 (19), DRBP1 (26), BM1258 (40) \\
\hline 24 & 3 & 12 & 0.48 & MCM136 (0), BMS1332 (38), BMS2526 (41) \\
\hline 25 & 3 & 12 & 0.51 & BP28 (0), INRA206 (12), TGLA40 (26) \\
\hline 26 & 4 & 12 & 0.69 & HEL11 (0), INRABERN172 (14), LSCV52 (22), LSCV46 (42) \\
\hline 27 & 3 & 11 & 0.55 & BM6526 (0), CSSM43 (8), TGLA179 (30) \\
\hline
\end{tabular}

a Average information content across chromosome.

between studies. In this study several putative QTL were identified for CF, SF, FW and FD and one each for SDA, SDFD and CVFD. It is interesting to note that most QTL detected in the study were segregating in families 4 (fine fibre producers) and/or family 6 (strong fibre producers). These two families were also amongst the largest included, and it was thus more likely that a segregating QTL could be detected in them.

Fleece weight remains one of the major traits that affect profit in the Angora goat industry. Three QTL for FW (on CHI 2, 5 and 24) were identified in this study. The putative QTL on CHI 5 had the largest effect (0.5) on this trait and explained $10.3 \%$ of the variance for this trait, while the QTL on CHI 2 and 24 explained between $8.8 \%$ and $13.4 \%$ of the variance respectively. Several studies have located a putative QTL for fibre yield on CHI 5 of Rayini goats (Mohammed Abadi et al., 2009), Angora $\times$ Creole goats (Debenedetti et al., 2010), purebred Angora goats (Cano et al., 2009b) and on the corresponding ovine chromosome (OAR 3) of Merino sheep (Roldan et al., 2010). QTL detecting in Rayini goats affecting cashmere hair traits resulted in QTL on chromosome 2, 5 and 13 of which those on chromosomes 2 and 5 overlap with the QTLs found on chromosome 2 and 5 for angora yield (trait FW). Moreover the QTL found for FW on chromosome 24 is not presented earlier and was also not detected in the cashmere study.

Table 3

Putative QTL identified for seven traits by chromosome.

\begin{tabular}{|c|c|c|c|c|c|c|c|}
\hline $\mathrm{CHI}$ & Trait & Position (cM) & F Statistic & F Threshold & Segregating family & Effect $/ S^{a}$ & Variance $^{\mathrm{b}}(\%)$ \\
\hline 1 & SDA & 121 & 5.15 & $5.13^{*}$ & 3 & -1.3 & 33.6 \\
\hline 2 & FW & 1 & 2.26 & $2.16^{*}$ & 10 & 0.4 & 8.8 \\
\hline 3 & SDFD & 62 & 2.68 & $2.67^{*}$ & 4 & 1.0 & 14.4 \\
\hline 4 & FD & 71 & 2.25 & $2.25^{*}$ & 12 & 1.7 & 8.3 \\
\hline 5 & FW & 1 & 2.52 & $2.35^{*}$ & 5 & 0.5 & 10.3 \\
\hline \multirow[t]{2}{*}{8} & $\mathrm{CF}$ & 21 & 2.15 & $1.88^{*}$ & 5 & 1.6 & 9.9 \\
\hline & SF & 4 & 2.22 & $2.18^{*}$ & 5 & -1.3 & 10.5 \\
\hline 12 & $\mathrm{CF}$ & 1 & 2.22 & $1.95^{*}$ & 6 & 0.9 & 10.5 \\
\hline \multirow[t]{2}{*}{13} & $\mathrm{CF}$ & 31 & 2.27 & $2.02^{*}$ & 6 & 0.2 & 14.6 \\
\hline & SF & 31 & 2.22 & $2.16^{*}$ & 6 & 0.03 & 14.0 \\
\hline 16 & $\mathrm{CF}$ & 68 & 2.15 & $1.92^{*}$ & 6 & 0.8 & 9.9 \\
\hline \multirow[t]{2}{*}{18} & $\mathrm{CF}$ & 26 & 2.31 & $1.84^{*}$ & 6 & 0.9 & 11.3 \\
\hline & SF & 26 & 2.07 & $2.07^{*}$ & 6 & -1.1 & 9.3 \\
\hline \multirow[t]{2}{*}{20} & $\mathrm{CF}$ & 32 & 2.15 & $1.89^{*}$ & 4 and 6 & 1.3 and 1.1 & 9.9 \\
\hline & $\mathrm{SF}$ & 32 & 2.33 & $2.24^{*}$ & 4 and 6 & -1.3 and -1.4 & 11.5 \\
\hline \multirow[t]{2}{*}{24} & FW & 41 & 2.93 & $2.71^{* *}$ & 4 & 0.3 & 13.4 \\
\hline & FD & 31 & 2.02 & $1.99^{*}$ & 4 & 0.7 & 6.9 \\
\hline 25 & CVFD & 22 & 2.73 & $2.47^{*}$ & 4 & 1.0 & 14.8 \\
\hline
\end{tabular}

a QTL allele substitution effect in significant sire family.

b \% of phenotypic variance explained.

* $p<0.05$ chromosome-wide significance.

** $p<0.01$ chromosome-wide significance. 


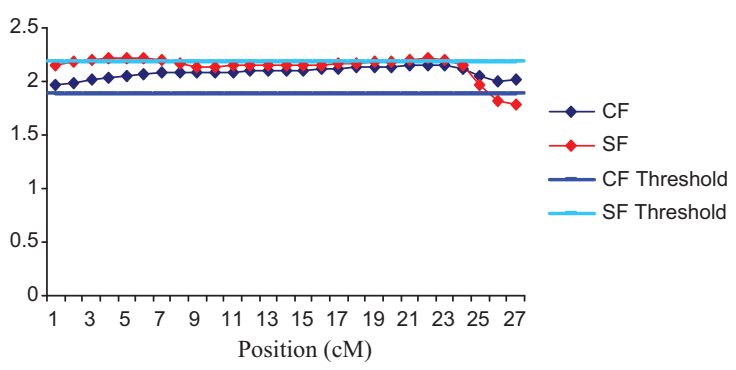

CHI 8
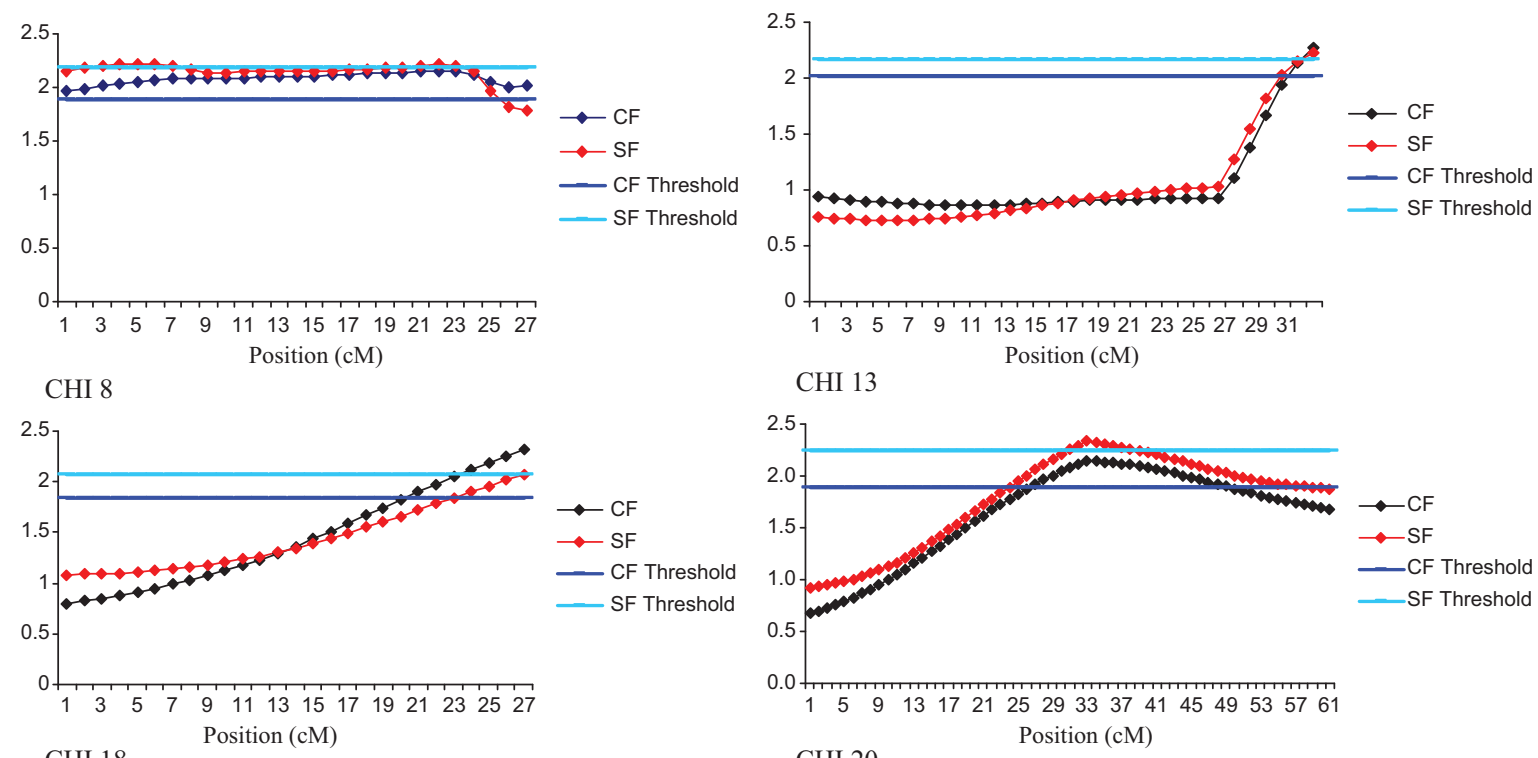

CHI 18
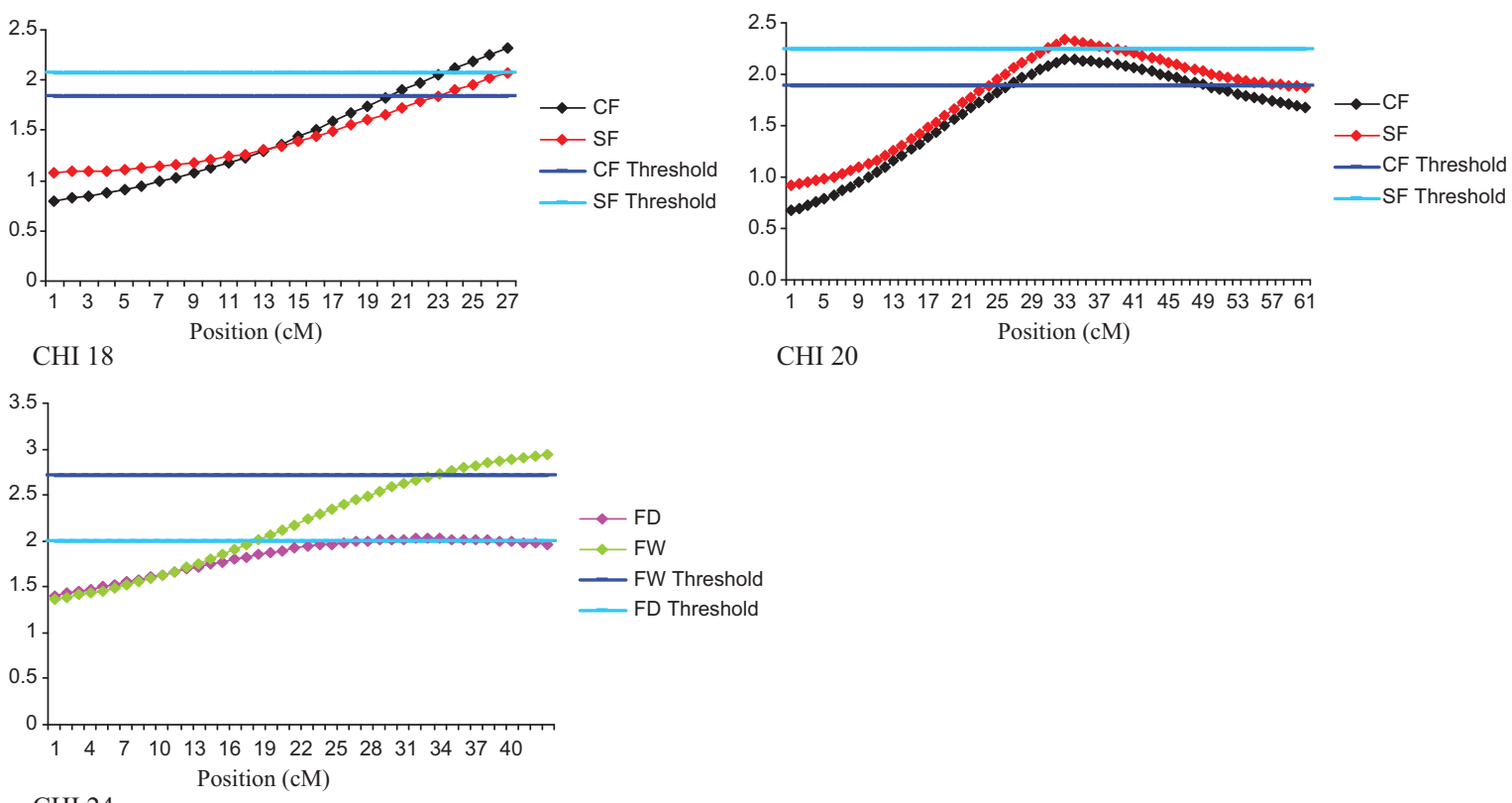

CHI 20

Position (cM)

Fig. 1. F-statistics depicting the locations of the putative QTL.

Two QTL associated with FD were identified on CHI 4 and 24 respectively in this study. A putative QTL for FD was reported by Cano et al. (2009b) on CHI 5, which was corroborated by Debenedetti et al. (2010) in an Angora $\times$ Creole backcross population where only $\mathrm{CHI} 5$ was investigated. QTL for wool fibre diameter have also been reported by Bidinost et al. (2008) on OAR 3 for FD at first shearing, and Roldan et al. (2010) on OAR 11 for FD at second shearing. When comparing QTL detected for the same traits at different shearing periods, Bidinost et al. (2008) reported that for some fleece traits QTL were only revealed at an early age, and not later in life and concluded that different genes could possibly be influencing the same trait at different stages in life. Detecting QTL on different chromosomes than Cano et al. (2009b) could be due to phenotypic traits measured at either second or third shearing in the current study, while samples were taken at 4 and 11 months of age in the study by Cano et al. (2009b). It should also be noted that all but one of the QTL detected was at chromosomewide significance level, as was those reported by Cano et al. (2007, 2009a,b) Further studies should focus on confirming the reported QTL at genome-wide significance levels in experimental designs with higher statistical power.
The unfavourable positive genetic correlation between FD and FW has been a challenge in Angora goat breeding strategies. Medium to strong genetic correlations have been reported, ranging between 0.35 (Allain \& Roguet, 2003) and 0.55 (Snyman \& Olivier, 1996). These traits are the main price-determining factors in the mohair industry, and optimisation of both has proved difficult. The detection of a QTL for FD on a separate chromosome (CHI 4) as for FW (CHI 2, 5 and 24), might pose an opportunity to decrease or maintain fibre diameter in Angora goats using marker assisted selection, while increasing fleece weight. It is however possible that a QTL affecting FW could also reside on $\mathrm{CHI} 4$, but that the statistical power in this study was limited to detect it. The second putative QTL for FD reported here is on the same chromosome as a QTL for FW (CHI 24).

Processing and fabric properties are influenced significantly by fibre diameter distribution (Qi et al., 1994; Smith et al., 2006) which are measured using OFDA2000 technology. The use of marker assisted selection to directly improve traits correlated with more uniform production (CVFD, SDFD, SDA) can contribute to a higher quality clip and improved attributes when compared to synthetic 
fibres. One putative QTL for CVFD was identified on CHI 25 in the current study. Putative QTL for CVFD on CHI 1, 2, 13 and 19 respectively were previously reported by Cano et al. (2007, 2009a, b).

The quality traits SDA and SDFD have not been included in previous QTL identification studies. The QTL for SDA segregating on $\mathrm{CHI} 1$ explains 33.6\% of the variance in the trait and is therefore the largest detected QTL effect in this study. Similar high variance values have been reported by Roldan et al. (2010) for fibre curvature (43.4\%) and fleece weight $(28.2 \%)$. The variance value reported here could however be an overestimation, and could be due to additional segregating QTL close to the putative position. A two-linked-QTL hypothesis should be tested for this trait. This trait has the lowest heritability of the quality traits included (Visser et al., 2009) and is largely affected by environmental and nutritional factors. Overestimation of the QTL effect could also be due to the pre-adjustment model of phenotypic records and herd effect. The amount of variance explained suggests that this chromosome segment could play an important role in improving fleece uniformity through MAS and should be further investigated. Quantitative selection for decreased variation in fibre diameter along the staple has not been successful and MAS can make a significant contribution to this trait.

The putative QTL identified for CF on CHI 8 has a relatively large effect of 1.6 which is possibly an overestimation. On four chromosomes ( $\mathrm{CHI} \mathrm{8,} \mathrm{13,} 18$ and 20) two putative QTL influencing CF and SF respectively, were detected. Taking into account the high genetic correlation $(-0.97)$ between these traits (Visser et al., 2009) and the close proximity of the estimated positions, it is probable that these QTL are single QTL affecting both traits. Two additional QTL were however identified influencing only CF (one each on CHI 12 and 16), suggesting that the two traits are under different genetic control, and cannot be considered as one. Spinning fineness and comfort factor are both unfavourably correlated with fleece weight. The identification of QTL which can be used to increase skincomfort traits without a negative correlated response in yield, might lead to a significant improvement in selection efficiency.

Mapping of keratin (KRT) and keratin-associated protein $(K A P)$ genes were performed in sheep, as these were expected to play an important role in wool traits. High glycine-tyrocine (HGT) KAPs as well as trichohyalin $(\mathrm{THH}$, a wool follicle protein) were mapped to ovine chromosome 1, while the high sulphur KAP gene families were shown to reside on OAR 3 and 19 (McLaren et al., 1997). A significant effect between high HGT loci and wool FD was observed by Parsons et al. (1994). Putative QTL for wool production and quality traits tend to cluster on OAR 1, 3, 4, 11 and 25 (Allain et al., 2006; Bidinost et al., 2008; Roldan et al., 2010), although a few have been reported on other chromosomes (Purvis \& Franklin, 2005). The overall resemblance between the ovine and caprine linkage maps are good, with OAR 1 mapping to CHI 1 and 3; OAR 3 to CHI 5 and 11; OAR 4 to CHI 4, OAR 11 to CHI 19 and OAR 25 to $\mathrm{CHI} 28$. Some of the KRT and KAP genes have been assigned to the goat genome, specifically $\mathrm{CHI} 1$ and 5 (Cano et al., 2007), and it was expected to find fibre-associated QTL on these chromosomes as well as the equivalents of the ovine chromosomes mentioned above. The results presented in this paper support the suggestion that KRT and KAP could be possible candidate genes for fibre yield and quality and should receive further attention in fibre-producing goats.

Molecular studies are performed at a high cost and using out-bred populations often limit the potential of having large numbers of offspring per sire with complete phenotypic data, especially OFDA data at an additional cost. Genotyping more offspring per family and larger family sizes will be advantageous for further studies. The large confidence intervals for the putative QTL were unfavourable, and could be improved by adding more markers and increased genome coverage. This study was quite robust and all but one QTL was verified at chromosome-wide significance level. The large QTL effect for SDA and variance estimate for CF (CHI8) appears to be over-estimations and could be further investigated in QTL verification and fine-mapping studies. When SNP arrays become available for goats, association studies could possibly be considered as an alternative to QTL studies. Their applicability in the South African goat industry will however depend on overcoming financial and resource constraints. This study presented sufficient evidence for QTL for mohair traits to warrant further study that will focus on fine mapping of these candidate regions.

\section{Conclusion}

Identifying causative mutations for economically important traits is dependent on QTL identification and mapping. The results of this study indicated several QTL of medium effect influencing mohair production and quality, and explain some of the genetic variance (ranging between 6.9\% and 33.6\%) in mohair traits. Two QTL influencing FD in mohair was reported in this study. One of these QTL was not linked to a QTL affecting FW, posing an opportunity to improve one trait without a negative correlated response in the other. The unfavourable correlations between FW and both SF and CF could be addressed in the same way. Alternative hypotheses including a single QTL controlling more than one trait and two linked QTL controlling a single trait should be investigated. Further studies should be conducted to fine-map these regions and detect favourable alleles, that could be incorporated into selection strategies through marker-assisted selection.

\section{References>}

Alan, M.F., Smith, T.P.L., 2008. Present and future applications of DNA technologies to improve beef production. Meat Sci. 80, 79-85.

Allain, D., Roguet, J.M., 2003. Genetic and non-genetic factors influencing mohair production traits within the national selection scheme of Angora goats in France. Livest. Prod. Sci. 82, 129-137.

Allain, D., Schibler, L., Mura, L., Barillet, F., Sechi, T., Rupp, R., Casu, S., Cribiu, E., Carta, A., 2006. QTL detection with DNA markers for wool traits in a sheep backcross Sarda $\times$ Lacaune resource population. In: In Proc 8th World Congress on Genetics Applied to Livestock Production , August 13-18, 2006. Brazil Communication, Belo Horizonte, pp. 05-07.

Bidinost, F., Roldan, D.L., Dodero, A.M., Cano, E.M., Taddeo, H.R., Mueller, J.P., Poli, M.A., 2006. Quantitative trait Loci related to Merino sheep wool quality. In: In Proc 8th World Congress on Genetics Applied to Livestock Production , August 13-18. Brazil Communication, Belo Horizonte, pp. 5-11. 
Bidinost, F., Roldan, D.L., Dodero, A.M., Cano, E.M., Taddeo, H.R., Mueller, J.P., Poli, M.A., 2008. Wool quantitative loci in Merino sheep. Small Rumin. Res. 74, 113-118.

Cano, E.M., Daverio, S., Cáceres, M., Debenedetti, S., Costoya, S., Abad, M., Allain, D., Taddeo, H., Poli, M.A., 2009a. Detection of QTL affecting fleece traits on CHI 19 in Angora goats. Trop. Subtrop. Agroecosyst. $11,189-191$.

Cano, E.M, Debenedetti, S., Abad, M., Allain, D., Taddeo, H.R., Poli, M.A., 2009b. Chromosomal segments underlying quantitative trait loci for mohair production in Angora goats. AGRI 45, 107-112.

Cano, E.M., Marrube, G., Roldan, D.L., Bidinost, F., Abad, M., Allain, D., Vaiman, D., Taddeo, H., Poli, M.A., 2007. QTL affecting fleece traits in Angora goats. Small Rumin. Res. 71, 158-164.

Debenedetti, S., Cano, E.M., Abad, M., Allain, D., Taddeo, H., Poli, M., 2010. Detection of QTL affecting fleece traits on CHI 5 in a backcross Angora $\times$ Creole goats in Argentina-Preliminary results. In: In Proc 9th World Congress on Genetics Applied to Livestock Production, August 1-6, 2010. Germany Communication, Leipzig, p. 0764.

Dekkers, J.C.M., 2004. Commercial application of marker- and geneassisted selection in livestock: strategies and lessons. J. Anim. Sci. 82 (E Suppl.), E313-328.

Dodds, K.G., McEwan, J.C., Davis, G.H., 2007. Integration of molecular and quantitative information in sheep and goat industry breeding programmes. Small Rumin. Res. 70, 32-41.

Georges, M., Nielsen, D., Mackinnon, M., Mishra, A., Okimoto, R., Pasquino, A.T., Sargeant, L.S., Sorensen, A., Steele, M.R., Zhao, X., Womack, J.E., Hoeschele, I., 1995. Mapping quantitative trait loci controlling milk production in dairy cattle by exploiting progeny testing. Genetics 139 , 907-920.

Goddard, M., 2009. Genomic selection: prediction of accuracy and maximisation of long term response. Genetica 136, 245-257.

Gong, H., Zhou, H., Hickford, J.G.H., 2010. Diversity of the glycine/tyrosine rich keratin-associated protein 6 gene (KAP6) family in sheep. Mol. Biol. Rep., doi:10.1007/s11033-010-0074-6.

Itenge-Mweza, T.O., Forrest, R.H.J., McKenzie, G.W., Hogan, A., Abbott, J., Amoafo, O., Hickford, J.G.H., 2007. Polymorphism of the KAP1.1, KAP1.3 and K33 genes in Merino sheep. Mol. Cell. Probes 21, 338-342.

Jeon, J.T., Lee, J.H., Kim, K.S., Park, C.K., Oh, S.J., 2006. Application of DNA markers in animal industries. Aust. J. Exp. Agric. 46, 173-182.

Jin, M., Wang, L., Li, S., Xing, M.X., Zhang, X., 2010. Characterization and expression analysis of KAP7.1, KAP8.2 gene in Liaoning new-breeding cashmere goat hair follicle. Mol. Biol. Rep., doi:10/1007/s11033-0109968-6.

Knott, S.A., Elsen, J.M., Haley, C.S., 1996. Methods for multiple-mapping of quantitative trait loci in half-sib populations. Theor. Appl. Genet. 93, 71-80.

Marrube, G., Cano, E.M., Roldan, D.L., Bidinost, F., Abad, M., Allain, D., Vaiman, D., Taddeo, H., Poli, M.A., 2007. QTL affecting conformation traits in Angora goats. Small Rumin. Res. 71, 255-263.

McLaren, R.J., Rogers, G.R., Davies, K.P., Maddox, J.F., Montgomery, G.W., 1997. Linkage mapping of wool keratin and keratin-associated protein genes in sheep. Mamm. Genome 8, 938-940.
Mohammed Abadi, M.R., Askari, N., Baghizadeh, A., Esmailizadeh, A.K., 2009. A directed search around caprine candidate loci provided evidence for microsatellites linkage to growth and cashmere yield in Rayini goats. Small Rumin. Res. 81, 146-151.

Parsons, Y.M., Cooper, D.W., Piper, L.R., 1994. Evidence of linkage between high-glycine-tyrosine keratin gene loci and wool fibre diameter in a Merino half-sib family. Anim. Genet. 25, 105-108.

Pollak, E.J., 2005. Application and impact of new genetic technologies on beef cattle breeding: a "real world" perspective. Aust. J. Exp. Agric. 45, 739-748.

Purvis, I.W., Franklin, I.R., 2005. Major genes and QTL influencing wool production and quality: a review. Genet. Sel. Evol. 37 (Suppl. 1), S97-S107.

Purvis, I.W., Jeffery, N., 2007. Genetics of fibre production in sheep and goats. Small Rumin. Res. 70, 42-47.

Qi, K., Lupton, C.J., Pfeiffer, F.A., Minikhiem, D.L., 1994. Evaluation of the optical fibre diameter analyser (OFDA) for measuring fiber diameter parameters of sheep and goats. J. Anim. Sci. 72, 1675-1679.

Roldan, D.L., Dodero, A.M., Bidinost, F., Taddeo, H.R., Allain, D., Poli, M.A., Elsen, J.M., 2010. Merino sheep: a further look at quantitative trait loci for wool production. Animal 4 (8), 1330-1340.

Seaton, G., Hernandez, J., Grunchec, J.A., White, I., Allen, J., De Koning, D.J., Wei, W., Berry, D., Haley, C., Knott, S., 2006. GridQTL: a Grid Portal for QTL mapping of compute intensive datasets. In: Proceedings of the 8th World Congress on Genetics Applied to Livestock Production, August 13-18, 2006. Belo Horizonte, Brazil.

Smith, J.L., Purvis, I.W., Lee, G.J., 2006. Fibre diameter profiles - potential applications for improving fine-wool quality. Int. J. Sheep Wool Sci. $54,54-61$

Snyman, M.A., Olivier, J.J., 1996. Genetic parameters for body weight, fleece weight and fibre diameter in South African Angora goats. Livest. Prod. Sci. 47, 1-6.

Snyman, M.A., Olivier, J.J., 1999. Repeatability and heritability of objective and subjective fleece traits and body weight in South African Angora goats. Small Rumin. Res. 34, 103-109.

Snyman, M.A., 2002. Evaluation of a genetically fine mohair producing herd. Small Rumin. Res. 43, 105-113.

Van der Werf, J.H.J., 2007. Marker assisted selection in sheep and goats. In: Guimarães, E., Ruane, J., Scherf, B., Sonnino, A., Dargie (Eds.), MarkerAssisted Selection: Current Status and Future Perspectives in Crops, Livestock, Forestry and Fish. J. FAO, Rome, Italy, pp. 230-247.

Van der Werf, J.H.J., Marshall, K., Lee, S., 2007. Methods and experimental designs for detection of QTL in sheep and goats. Small Rumin. Res. 70, 21-31.

Visser, C., Snyman, M.A., Van Marle-Köster, E., Bovenhuis, H., 2009. Genetic parameters for physical and quality traits of mohair in South African Angora goats. Small Rumin. Res. 87, 27-32.

Visser, C., Crooijmans, R.P.M.A., Van Marle Köster, E., 2010. A genetic linkage map for the South African Angora goat. Small Rumin. Res. 93, 171-179.

Weller, J.I., Kashi, Y., Soller, M., 1990. Power of daughter and granddaughter designs for determining linkage between marker loci and quantitative trait loci in dairy cattle. J. Dairy Sci. 73, 2525-2537. 